\title{
A IMPORTÂNCIA DE UMA EDUCAÇÃOPARA OS SABERES ECOLÓGICOS NA FORMAÇÃO DA CRIANÇA AMAZÔNIDA NA PÓS-MODERNIDADE ${ }^{1}$
}

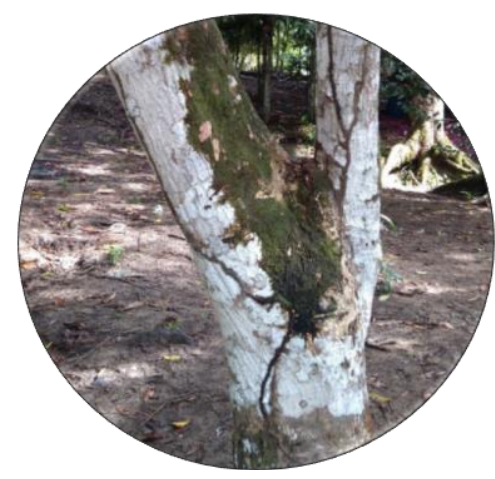

Gracy Kelly Monteiro Dutra Teixeira ${ }^{2}$ Maria Inês Gasparetto Higuchi ${ }^{3}$

\begin{abstract}
Resumo
Este artigo de revisão bibliográfica se propõe a discutir a importância de uma educação ecológica para a criança amazônica na pós-modernidade, a qual é o elemento fundamental para a retomada de um equilíbrio do ambiente físico. Parte-se do princípio epistemológico da Sociologia da Infância que empodera à criança o papel de protagonista na análise dos fenômenos sociais,e do conceito de Ecologia de Saberes elaborado por Boaventura de Sousa Santos (2006) na formação de uma educação além do paradigma hegemônico. Utilizou-se como respaldo teórico Leff (2001; 2006), Jacobi (2003; 2005), Higuchi (2004), Khan et al (1996; 2009), entre outros. É salientada a necessidade de uma educação voltada aos saberes ecológicos, para que haja a manutenção do ecossistema e prolongamento da vida terrestre.
\end{abstract}

Palavras-chave: Criança. Educação. Ruptura. Empoderamento. Ambiente.

\begin{abstract}
${ }^{1}$ Artigo elaborado na disciplina Sustentabilidade e Sociedade do Programa de Pós-Graduação em Ciências do Ambiente e Sustentabilidade na Amazônia (UFAM).

2Bacharel em Ciências Sociais (UFAM). Especialista em Educação para o Desenvolvimento Sustentável (UFAM). Mestranda do Programa de PósGraduação em Ciências do Ambiente e Sustentabilidade na Amazônia (UFAM). Docente da Universidade do Estado do Amazonas, Campus Parintins.

${ }^{3}$ Doutora em Antropologia Social pela Brunel University. Pesquisadora titular do Instituto Nacional de Pesquisas da Amazônia. Coordenadora do Laboratório de Psicologia e Educação Ambiental.
\end{abstract}


This literature review aims to discuss the importance of environmental education for the child Amazon in postmodernity, which is the key element for the resumption of a balance of the physical environment. This is on the epistemological principle of sociology of childhood that empowers the child the starring role in the analysis of social phenomena, and the concept of the Knowledge Ecology prepared by Boaventura de Sousa Santos (2006) in the formation of an education beyond the hegemonic paradigm. Was used as theoretical support Leff (2001; 2006) and Jacobi (2003; 2005), Higuchi (2004) Khan et al (1996; 2009), among others. It stressed the need for an education geared to ecological knowledge, so there is the maintenance of the ecosystem and prolongation of earthly life.

Keywords: Children. Education. Break. Empowerment. Environment.

\section{INTRODUÇÃO}

Pensar em criança na pós-modernidade é vislumbrar um sujeito social com potencialidades de consumo e entendimento acerca do mundo, isto é, ser criança hoje é estar incutido num mundo de retórica capitalista que caminha em todas as classes e em todas as gerações.

Pensar na sociedade pós-moderna é conjecturar alternativas distintas daquelas que são naturalizadas pelo cotidiano do paradigma hegemônico, no qual a busca pelo lucro, exacerbação do consumo e endeusamento da ciência como a única verdade são característicos desta estrutura ideológico-social.

Nesta pós-modernidade, tornam-se urgentes proposituras que busquem a compreensão das alteridades socioculturais e opções para uma nova forma de relações sociais e de convívio com o ambiente físico, por isso, há a imperiosa necessidade da sustentabilidade nas discussões do conjunto social e na formação do ser social. É neste universo que a criança do $3^{\circ}$ milênio vive, e ainda mais, especificamente, a criança ribeirinha amazônida que convive ao seu redor com a floresta, a terra e a água.

É no cotidiano amazônico, entre a ruralidade e a urbanidade do ambiente, que a criança percebe o "ir" dos recursos naturais e o "vir" de novas tecnologias, é neste percurso de percepção ambiental que a criança ribeirinha torna-se elemento-chave para a afirmação de uma educação 
voltada aos saberes ecológicos, a qual possa empoderar a sociedade sobre alternativas à crise ambiental que permeia o século 21; é salutar observar que as posteriores assertivas baseiam-se no campo da Sociologia da Infância, no qual a criança é o ponto crucial para compreensão dos fenômenos sociais.

\section{Criança e Infância: conceitos distintos.}

Discutir a problemática ambiental a partir da criança é empoderála, efetivamente, de direitos e potencialidades no conjunto social, o qual na sua enculturação, através do ambiente familiar e instituição escolar, é que se percebe o alcance do habitus circundante na sociedade, as regras, os costumes e as interações fomentadas pela atual sociedade capitalista globalizada. Daí a importância da criança ser o elemento norteador de nossa retórica entre o ser humano e a natureza.

Para Sarmento (2005, p. 363), tomar as crianças como objeto de investigação científica é imprescindível para vislumbrar as relações e os processos sociais atuais, dotando-as de um protagonismo antes inexistente no campo científico. É importante frisar, que foi na metade do século 20 que a criança passou a ser considerada como cidadão de direitos, além de que foi neste tempo, que ela passou a ser protegida das questões adultas como o sexo e a violência, num sentido de preservar o ser em formação e prepará-lo para o futuro (BELLONI, 2009, p. 116).

Esta ruptura conceitual do ser criança correspondeu a um trabalho de separação do mundo dos adultos e de institucionalização das crianças (Sarmento, 2005, p. 367). É a partir desse processo de rompimento ideológico que a criança passa a viver sua infância, não sendo mais tratada como adulto em miniatura, que necessita passar pela mesma carga de responsabilidades que o ser adulto. Mas, qual a distinção entre infância e criança? 
Sarmento não aponta um conceito claro que as diferencie, porém, apresenta a infância como independente da criança (2005, p. 364), podendo-se vivê-la sem estar na faixa de idade até doze anos ${ }^{\mathrm{i}}$. Um exemplo para esta representação é o cantor estadunidense Michael Jackson (1958 2009), que viveu sua infância na idade adulta, construindo um parque de diversões para si intitulado Neverland (A terra do nunca), uma referência ao livro "Peter Pan" de J. M. Barrie (1860 - 1937). Por isso, Sarmento (2005, p. 365) comporta a infância como historicamente construída e na qual se revelam as possibilidades e os constrangimentos da estrutural social.

A vida cotidiana das crianças comporta, como qualquer outra, sua parte de alienação a rotinas mais ou menos constrangedoras, de cotidianidade, no sentido em que Lefèbvre dava a este termo. Para as crianças, não se trata apenas de assimilar as disciplinas que lhes devem permitir se integrarem nos diversos grupos dos quais elas fazem parte, mas também de consolidar o sentimento de segurança ontológica (Giddens), sem o qual a existência no dia-a-dia só pode ser uma aventura terrífica. Infelizmente é verdade que, atualmente, o terror é a sina de muitas crianças. Mas, se a sociedade das crianças comporta projetos, ela é também, balizada por ritos, frutos, muitas vezes, de transações espontâneas com o mundo dos adultos (JAVEAU, 2005, p. 386).

Esta conformação social é a estrutura modal para a naturalização dos costumes e regras sociais nos seres humanos, estritamente indispensável para o fortalecimento e entrelaçamento do corpo societário. É durante esta fase que a criança adquire a distinção entre o certo e o errado, por isso, se o ambiente familiar em conjunto com a escola proporcionar coerentes discussões e exemplos, possibilitará uma desfamiliarização de conceitos preexistentes e alterações em novas práticas; se a criança compreender que jogar lixo em qualquer ambiente faz mal e que depredar a natureza pode reduzir os níveis de vida terrestre, o futuro 
das espécies poderá ser prolongado com ações que legitimem a sustentabilidade ambiental, como valor intrínseco ao ser humano.

\section{A crise ambiental como crise da racionalidade científica: conjecturas teóricas.}

A sustentabilidade socioambiental é um processo contínuo de internalização de novas práticas e externalização de novas ações, ou seja, é uma construção perene que perpassa por inúmeras gerações, portanto, o elemento inicial deve ser a criança, sujeito social capaz de alterar a realidade vivenciada hoje pelo meio ambiente.

A questão da sustentabilidade socioambiental é algo presente no cotidiano, mas para estar em voga é porque amiúde lançou-se como inquietação à comunidade acadêmica e científica. $\mathrm{O}$ ponto fundante para a complexificação da temática ambiental no âmbito da ciência foi a realização da Conferência de Estocolmo em 1972, que abordou a chuva ácida e o controle da poluição do ar que ameaçava a qualidade de vida (NASCIMENTO, 2012).

Tanto a chuva ácida ${ }^{\text {ii }}$ quanto a poluição atmosférica tem origem na ação antrópica, oriunda da Revolução Industrial. Essa revolução transformou para sempre os rumos da humanidade, legando aos seres humanos a exclusão, marginalização e exploração, tudo isso proporcionado pela racionalidade científica, por isso, a relação entre crise ambiental e crise do conhecimento.

Milton Santos (2011) discute que o desenvolvimento da história vai de par com o desenvolvimento das técnicas, e estas evoluem devido à evolução do pensamento e ao avanço da ciência. Leff (2001) aponta que o conhecimento científico proporcionou a crise ambiental que acima de tudo é uma crise do conhecimento. Essa racionalidade promoveu alterações socioambientais: extinções de espécies, desmatamento, mudanças 
climáticas, entre outros, que são viabilizados pelo conhecimento e aprimoramento das técnicas.

Esse processo evolutivo propicia uma busca pela "dominação" seja do ser humano quanto do ambiente físico, à medida que "o homo economicus substitui o homo sapiens na fase suprema da evolução rumo ao fim da história [...]" (Leff, 2001, p. 209), isso é uma situação obtusa que a ciência aliada aos interesses econômicos desenrolou, por isso que sustentabilidade e economia andam lado a lado.

A partir do surgimento da ciência econômica se estabelece uma racionalidade que começa a dominar a ordem natural das coisas do mundo, as formas de produção da riqueza, as regras de intercâmbio de mercadorias e o valor da natureza. Esta ordem econômica, fundada no "equilíbrio" dos fatores de produção sob o princípio da escassez, vai construindo uma racionalidade que leva, a princípio, à desnaturalização da própria natureza e à insustentabilidade do processo de produção (LEFF, 2005, p. 171-172).

E para superar a crise ambiental é preciso desconstruir o pensado, reapropriando-se de uma nova mentalidade, uma retorno à humanidade solidariedade, rompendo com a cultura hegemônica do "ter", para isso, precisa-se não tratar a natureza como objeto, mas viabilizar a renovação e manutenção dos recursos naturais.

Santos (2011, p. 88) argumenta que o avanço da civilização atribui ao homem, por meio do aprofundamento das técnicas e de sua difusão, uma capacidade cada vez mais crescente de alterar os dados naturais quando possível, reduzir a importância do seu impacto e, também, por meio da organização social, de modificar a importância de seus resultados. Por isso, a crise ambiental torna-se a crise da razão e se faz necessário uma reconstrução do conhecimento do mundo a partir dos saberes ecológicos, no qual a ciência irá postular por uma nova prática e alternativa paradigmática, onde a educação irá preparar “as novas gerações não apenas 
para que aceitem a incerteza" (Leff, 2001, p. 219), contudo, também irá promover uma nova mentalidade sobre o Ser no mundo.

Trata-se de uma educação que permite que os indivíduos se preparem para a construção de uma nova racionalidade; não para uma cultura da desesperança e alienação, mas pelo contrário, para um processo de emancipação que permita o surgimento de novas formas de reapropriação do mundo (LEFF, 2001, p. 219).

Fomentar uma educação direcionada aos saberes ecológicos na pós-modernidade, em especial na criança amazônida, é crucial para a efetividade da sustentabilidade socioambiental no cotidiano amazônico, à medida que debate-se a fragilidade dos recursos naturais com o avanço da tecnologia expõem-se a própria fragilidade humana, por isso, Boaventura de Sousa Santos (2001) argumenta que a ciência moderna não erradica os riscos, as violências e as ignorâncias, mas os amplia, recriando-os através de uma nova relação de propriedade.

O risco é actualmente o da destruição maciça através da guerra ou salidade entre as acções e suas consequências; a violência continua a ser a velha violência da bubris industrial relativamente aos sistemas ecológicos e à violência simbólica que as redes mundiais da comunicação de massa exercem sobre as suas audiências cativas (SANTOS, 2001, p. 58).

É preciso reconstruir o senso introjetado pelo paradigma dominante e instituído com legítimo pela ciência moderna, visualizando o risco que se corre ao permeá-lo no cotidiano. Ratifica-se a esse comentário, o argumento de Morin (2000, p. 19): “Todo conhecimento comporta o risco do erro e da ilusão. A educação do futuro deve enfrentar o problema da dupla face do erro e da ilusão". O conhecimento proporciona libertação, mas esta liberdade pode tornar-se uma prisão libertina, onde a ignorância da altivez e da unificação dos indivíduos bloqueia enxergar as diversidades 
de culturas, e é isto que se quer romper com uma educação voltada ao saber ecológico.

Ainda nesse foco, Jacobi (2003, p. 192) assevera que o tema sustentabilidade confronta-se com o paradigma da "sociedade de risco", o que implica a necessidade de se multiplicarem as práticas sociais baseadas no fortalecimento do direito ao acesso à informação e à educação ambiental em uma perspectiva integradora, por isso, postular práticas ecológicas a partir da criança é proporcionar um futuro mais equilibrado e saudável ao ambiente como um todo, tornando-o, efetivamente, o direito essencial à sadia qualidade de vida.

Santos (2006) enfatiza que esse mundo programado pela ciência moderna, a qual vislumbra um mundo uniforme e vertical, postula-se por hierarquias culturais e tidas como verdades, já que para este autor, a ciência moderna tem um pensamento abissal no qual há dois universos distintos: "a característica fundamental do pensamento abissal é a impossibilidade da copresença dos dois lados da linha” (p.32), só há uma lado verdadeiro e digno de considerações, o outro, é primitivo e subalterno.

Neste acorde teórico, a prática do socioambientalismo e multiculturalismo ${ }^{\mathrm{iii}}$ no processo educativo promoverá uma sociedade equitativa e ecológica, onde a urgência de um novo senso na pósmodernidade é viabilizado pela "Ecologia dos Saberes".

\footnotetext{
A ecologia de saberes é um conjunto de epistemologias que partem da possibilidade da diversidade e da globalização contra-hegemônica e pretendem contribuir para as credibilizar e fortalecer. [...]. Quando falo de ecologia dos saberes, entendo-a como ecologia de práticas de saberes (SANTOS, 2006, p. 154).
}

Por isso, que Boaventura Santos salienta que pensar o conhecimento no século XXI, é vislumbrar o mundo a partir da multiculturalidade e na diversidade da prática de saberes, no qual o saber propositivo é inerente à reconfiguração da ciência e do conhecimento, 
argumento coerente com os rumos almejados à interculturalidade da Região Amazônica.

Trata-se de uma ecologia porque assenta no
reconhecimento da pluralidade de saberes
heterogêneos, da autonomia de cada um deles e da
articulação sistêmica, dinâmica e horizontal entre eles.
A ecologia dos saberes assenta na independência
complexa entre os diferentes saberes que constituem o
sistema aberto do conhecimento em processo constante
da criação e renovação. O conhecimento é
interconhecimento, é reconhecimento, é
autoconhecimento (SANTOS, 2006, p. 157).

A ecologia da prática de saberes possibilita uma emancipação cultural dos povos antes considerados como atrasados e primitivos, promovendo o saber antes alijado como conhecimento. Leff apud Silva et al (s/d) afirma que o princípio da sustentabilidade trata-se da reapropriação da natureza e de reinventar o mundo, pois surge como uma resposta frente à modernização a partir da reconstrução de uma nova racionalidade produtiva, apoiada no potencial ecológico e em novos sentidos de civilização com a diversidade cultural do gênero humano.

\begin{abstract}
A sustentabilidade como novo critério básico e integrador precisa estimular permanentemente as responsabilidades éticas, na medida em que a ênfase nos aspectos extra - econômicos serve para considerar os aspectos relacionados com a equidade, a justiça social e a ética dos seres vivos (JACOBI, 2005, p. 10).
\end{abstract}

Educar a criança amazônida no respeito ao meio ambiente estabelece um prolongamento na disposição dos recursos e da vida terrestre, dotá-la de um senso crítico perante as alterações ambientais estimula à efetividade dos direitos sociais, por isso, a necessidade urgente no século 21 de uma educação voltada ao saber ecológico, à afirmação da sustentabilidade como direito inerente dos sujeitos. 


\section{Sustentabilidade socioambiental como direito humano da criança.}

Um ecossistema equilibrado contribui para o bem-estar da população, possuir um ambiente físico saudável é um direito social de qualquer ser humano, à medida que influencia os aspectos internos e externos da qualidade de vida.

Em vista disso, a criança precisa viver num ambiente ecologicamente sadio e com equidade social, por isso, a Constituição Brasileira de 1988, denominada Constituição Cidadã, no artigo 227, institui como dever da família, da sociedade e do Estado assegurar à criança e ao adolescente com absoluta prioridade, o direito à vida, à saúde, à alimentação, à educação, ao lazer, à profissionalização, à cultura, à dignidade, ao respeito, à liberdade e à convivência familiar e comunitária, além de colocá-los a salvo de toda forma de negligência, discriminação, exploração, violência, crueldade e opressão.

Como ter "direito à vida, à saúde, à alimentação" sem manter a renovação dos recursos naturais? É preciso postular práticas socioambientais que se fundamentem na renovação da vida e conservação ambiental, por isso, a necessidade de uma educação realmente eficaz e includente entre o ser social e a natureza. Corroborando a tal assertiva, Vieira e Santos (2005) discutem que o direito das crianças e adolescentes constitui uma entrada para a prática do socioambientalismo, visto ser este uma construção teórica que fixa seus fundamentos na ideia de que as políticas públicas devem incluir e envolver as comunidades locais detentoras de conhecimentos e práticas específicas, promovendo a sustentabilidade socioambiental e o multiculturalismo.

A prática socioambiental tem como marco jurídico a Constituição de 1988, quando os diversos grupos sociais foram atendidos na promulgação da Carta Magna: negros, mulheres, indígenas, pessoas com 
necessidades especiais, idosos, crianças e adolescentes, além da proteção ao patrimônio público e social, patrimônio cultural e meio ambiente. Estes direitos institucionalizados foram denominados como direitos da $3^{\mathrm{a}}$ dimensão ${ }^{\text {iv }}$, por tratar-se de bens coletivos, transgeracional, de uso comum e de interesse público (Vieira e Santos, 2005).

Ter acesso a sombreamento arbóreo, lagos, igarapés e rios sem resíduos sólidos, ar sem poluição, entre outros, é direito de qualquer sujeito, principalmente da criança que precisa se reconhecer como parte de um ecossistema maior e complexo que se retroalimenta. Na Constituição Federal, o artigo 225 determina que:

Todos têm direito ao meio ambiente ecologicamente equilibrado, bem de uso comum do povo e essencial à sadia qualidade de vida, impondo-se ao poder público e à coletividade o dever de defendê-lo e preservá-lo para as futuras gerações.

Questiona-se o papel do poder público na resolução de alternativas que freiem com os problemas ambientais, e além dele, e principalmente, da iniciativa privada, que subjuga a resiliência da natureza em prol do lucro das empresas. Todavia, a ação principal é dos atores coletivos que precisam - urgentemente- reconstruir suas ideologias baseadas no paradigma dominante e instituir uma nova prática ecológica, no qual o pensar em sustentabilidade é pensar em uma nova postura na relação com o outro e com as coisas e nas possibilidades de emancipação humana, na qual o ideal é o ser-mais e o ser-melhor. Daí o foco de mudança partir da educação, seja ela em casa ou na escola, a qual precisa livrar-se das amarras impostas por um modelo que subjuga as coisas e aliena o sujeito, para que haja garantias de um ambiente favorável e resiliente, sem comprometimento do lado social e econômico. 


\section{A criança, a educação para os saberes ecológicos e o exemplo de um espaço amazônico.}

A Amazônia é adjetivada como o pulmão do mundo, possuindo o tamanho de quase 6 milhões $\mathrm{Km}^{2}$, maior que a Europa Ocidental e quase tão grande quanto os EUA, todavia, a destruição desta floresta é crescente assim como a urbanização das áreas verdes, com a implantação de centros urbanos.

Esta urbanização diminui a mata ciliar e traz inúmeras situaçõesproblemas à população, um deles é o lixo que torna-se "adorno" dos rios e das ruas, prejudicando famílias e o bem-viver da coletividade. Kloetzel (2002, p. 11) alerta que:

São tantos os problemas neste planeta (da feroz abelhaafricana à usina atômica, do ameaçado mico-leão ao efeito estufa) e tão frágeis as fronteiras entre países que, para encontrarmos soluções, é necessário um trabalho em conjunto, um esforço verdadeiramente transnacional.

Não depende de um só sujeito, mas sim, da união de forças de todas as pessoas em prol do meio ambiente - a criança hoje, o "cidadão do futuro", precisa estar infundido nesta coletividade, pois, "o meio ambiente pertence à coletividade dos homens, das nações. Se hoje despejo meu lixo no terreno vizinho, amanhã ele fará o mesmo comigo; logo, é preferível formarmos uma frente única” (KLOETZEL, 2002, p. 11).

As problemáticas ambientais precisam ser urgentemente combatidas e a educação torna-se fundamental na reconquista do ambiente, claro, que é um processo longo, uma vez que a geração de hoje precisa reestruturar as ações das gerações passadas.

Jacobi (2003) discute que a reflexão sobre as práticas sociais, em um contexto marcado pela degradação permanente do ecossistema, envolve uma necessária articulação com a produção de sentidos sobre educação 
ambiental, mas, não como uma disciplina específica, mas algo transdisciplinar, uma educação em todos os espaços.

A realidade atual exige uma reflexão cada vez menos linear, e isto se produz na inter-relação dos saberes e das práticas coletivas que criam identidades e valores comuns e ações solidárias diante da reapropriação da natureza, numa perspectiva que privilegia o diálogo entre saberes (JACOBI, 2003, p. 191).

A criança amazônida urbana no século 21 precisa apreender o que é um ambiente equilibrado, o que é um rio e uma rua sem resíduos sólidos, visto que, muitas vezes, cresce próximo a um curso d'água poluído e supõese que ela ache que é natural ser o rio fétido e degradado. Khan et al (2009) aponta esta naturalização da degradação ambiental no contexto da criança na pós-modernidade como uma "amnésia ambiental geracional":

The cru xis that, with each ensuing generation, the amount of environmental degradation caan increase, but each generation tends to take that degraded condition as the nondegrade condition - that is, as the normal experience - a condition that Khan (1999, 2002) has termed environmental generational amnesia (KHAN et al, 2009, p. 41).

Não conhecer o meio ambiente como de fato ele deve ser, reduz a qualidade da vida humana e escandaliza a noção de direito humano estampado na CF no artigo 225, por isso, que educar para os saberes ecológicos é primordial no cotidiano, ou conforme, Jacobi ( 2003) e Higuchi (2004) viabilizam como Educação Ambiental.

A educação ambiental insere-se no cenário moderno a fim de gerar modificações nos valores e comportamentos pessoais, tal discussão é postulada pelos preceitos das dimensões de sustentabilidade no enfrentamento da crise ambiental, isso se confirma com o sentido exposto por Santos (2006) sobre a Ecologia de Saberes, exposto a priori. 
Podemos afirmar que a Educação Ambiental é o palco principal no cenário das discussões sobre sustentabilidade, uma vez que seu foco parte das mudanças em valores, atitudes e comportamento, desenvolvendo nas pessoas um comprometimento não apenas com o meio ambiente quando se refere aos recursos naturais, mas com os outros diversos ambientes, em casa, na escola, na comunidade, no trabalho, e outros (SILVA et al, s/d, p. 3-4).

É necessário transformar os valores de hoje, corromper o paradigma dominante e viabilizar o enaltecimento das interculturalidades e da conscientização da finitude dos recursos, assim, as ações sustentáveis não irão se restringir apenas a questões referentes ao lixo, poluição, desmatamento, mas, em algo mais abrangente, visto que sua retórica caminha por "mudanças em atitudes, afetos e comportamentos socioambientais" (Silvaet al, s/d, p. 12).

Higuchi e Azevedo (2004) corroboram ainda que a Educação Ambiental requer a construção de novos objetos interdisciplinares de estudo através da problematização de paradigmas dominantes, da formação de docentes, da incorporação do saber ambiental emergente em novos programas curriculares e nos programas com as comunidades, sejam urbanas ou rurais. Pensar na Amazônia não somente como floresta “intocada", mas, nos povos que vivem nela, seja no rural quanto no urbano, que sofrem diretamente com os avanços tecnológicos e a redução do ambiente físico.

[...] EA é ideológica no sentido político, portanto, não é neutra, nem contextualizada, nem acrítica; a abordagem deve ser mais ampla e relacional possível, considerando as problemáticas globais, suas inter-relações; deve promover o diálogo e a cooperação entre indivíduos, instituições e culturas; [...] (HIGUCHI e AZEVEDO, 2004, p. 67). 
Os indivíduos da pós-modernidade precisam incutir-se desse conceito, transformando-o em ações transformadoras no ambiente, visto que, educar hoje para os saberes ecológicos envolve não somente os pais e a escola, mas, principalmente as novas mídias, devido à interatividade e globalização das informações. Afinal, a crise ambiental é a crise do conhecimento científico, por isso, Khan (2008), aponta que "techonology has begun to change our species long-standing experiences nature. Now we have technological nature - technologies that in various ways mediate, angment, or simulate the natural world"(p. 37), todavia, nada melhor do que vislumbrá-la ao vivo e em cores.

Este mesmo autor realizou na década de 1990 um estudo na Amazônia acerca da percepção da criança brasileira amazônica sobre a degradação ambiental, o qual constatou que as crianças sabem que jogar lixo no rio causa um grande mal ao ambiente e que afeta muitas vidas, o interessante é notar que das duas cidades envolvidas (Manaus e Novo Airão no Amazonas), as crianças da cidade interiorana tem mais apelo no combate à degradação ambiental do que as da capital.

The majority ot the fifth-grade urban and rural Brazilian children we interviewed demonstrated environmental sensitivities and commitments based on a wide range of measures.[...]. They believed that throwing garbage in the Rio Negro hurt various parts of the environment (namely, birds, insects, the view, and people who lived alongside the river), and they cared that such harm ocurred (KHAN et al, 1996, p. 985).

Apesar do fato de a criança de um grande centro urbano ter menos sensibilidade ambiental, não a impede de buscar por uma nova prática ecológica, porém, isso depende da família, da comunidade, enfim, de toda a coletividade. Não naturalizar o ambiente físico poluído e degradado é ponto-chave para uma nova sociedade e, por conseguinte,uma nova prática educativa.

Uma educação voltada aos saberes ecológicos busca almejar uma outridade para o homo sapiens, no qual possa-se repensar os rumos do 
conhecimento, romper com o paradigma alienante e excludente, adquirindo uma outra visão sobre as coisas e os sujeitos, enfim, que se retorne a humanidade - solidariedade perdida pela procura do lucro e ampliação das novas tecnologias.

\section{Considerações Finais}

A discussão teórica apresentou as possibilidades da educação voltada aos saberes ecológicos na criança na pós-modernidade, em especial a amazônica, analisando a crise ambiental como a crise da racionalidade científica e os desdobramentos dessa fragilidade no direito humano de possuir um ambiente sadio e equilibrado.

A análise tem, como ponto de transformação do ambiente e de suas relações, o ser criança, o qual tem potencialidades e possibilidades de alterar a realidade vivenciada hoje sobre os problemas ambientais, todavia, afirmando o papel da coletividade para a construção dessa identidade transformadora. Se a criança é o cidadão do futuro, como o senso comum propaga, é ideal que a sociedade promova esse caráter libertário, inquietante, estratégico e, porque não dizer de esperança sobre os rumos do ambiente e dos seres humanos. E o caminho para que isso aconteça é através da educação: em casa, na rua, na escola, isto é, em qualquer ambiente que aconteça relações sociais.

Em suma, a criança na pós-modernidade deve ser levada a não conformar-se com o que está posto, deve rebelar-se e buscar alternativas diferentes àquilo que lhe ensinado como natural, somente assim, o ambiente estará protegido e junto com ele todas as espécies ainda vivas no planeta, deste modo, superar-se-áa crise ambiental como crise do conhecimento e o direito à boa qualidade de vida será, de fato, atingido. 
'No Brasil, o Estatuto da Criança e do Adolescente de 1990 considera criança a pessoa até doze anos de idade incompletos e adolescente a faixa etária entre doze e dezoito anos.

iiA chuva ácida é um fenômeno local, pois a composição da chuva depende dos poluentes lançados naquele local específico. Os principais agentes poluidores são os óxidos de enxofre e nitrogênio, que, dissolvidos em água, formam os ácidos sulfúrico e nítrico.

iiiMulticulturalismo é uma estratégia política de reconhecimento e representação da diversidade cultural, não podendo ser concebido dissociado dos contextos de lutas dos grupos culturalmente oprimidos.

iv Os direitos de $3^{\mathrm{a}}$ dimensão surgiram como resposta à dominação cultural e reação ao alarmante grau de exploração, não mais da classe trabalhadora dos países industrializados, mas das nações em desenvolvimento por aquelas desenvolvidas e dos quadros de extrema injustiça do ambiente dessas nações.

\section{REFERÊNCIAS}

BELLONI, Maria Luiza. O que é Sociologia da Infância. Campinas, SP: Autores Associados, 2009.

BRASIL. Constituição da República Federativa do Brasil de 1988. Disponível em $<<$ http://www.planalto.gov.br/ccivil_03/constituiçao/constituição.htm> $>$. Acesso em: 05 de maio de 2013.

BRASIL. Estatuto da Criança e do Adolescente: Lei 8. 069/90. Rio de Janeiro: Roma Victor, 2010.

FRANCISCO, Regina Helena Porto. Meio Ambiente e Chuva Ácida. Disponível em $<<$ http://www.cdcc.usp.br/ciencia/artigos/art 15/chuvaacida.html $>>$.

Revista Eletrônica de Ciências. Número 15. Acesso em: 01 de junho de 2013.

HIGUCHI, Maria Inês Gasparetto; AZEVEDO, Genoveva Chagas. Educação como processo na construção da cidadania ambiental. In: Revista Brasileira de Educação Ambiental - no 0 (nov 2004). Brasília: Rede Brasileira de Educação Ambiental, 2004.

JACOBI, Pedro. Educação Ambiental, cidadania e sustentabilidade. In: Cadernos de Pesquisa, n. 118, mp. a1rç8o9/-220050,3 março/ 2003. 
JACOBI, Pedro. Educar para a sustentabilidade: complexidade, reflexividade e desafios. In: Revista Educação e Pesquisa, volume 31/2 - maio-agosto 2005, FEUSP.

JAVEAU, Claude. Criança, Infância(s), Crianças: que objetivo dar a uma ciência social da Infância?. In: Educ. Soc., Campinas, vol. 26, n. 91, p. 379-389, Maio/Ago. 2005.

KHAN JR, Peter H.; HOWE, Daniel C.; FRIEDMAN, Batya. Along the Rio Negro: Brazilian Children's Environmental views and values. Developmental Psychology. Vol. 32 num. 6, 1996. p. 979 - 987.

KHAN JR, Peter H.; SEVERSON, Rachel L.; RUCKERT, Jolina H. The Human Relation with nature and technological nature. A jourof the association for psychological Science. Vol. 18 num. 1, 2009.

KLOETZEL, Kurt. O que é meio ambiente. São Paulo: Brasiliense, 2002.

LEFF, Enrique. A lei/limite da natureza: entropia, produtividade neguentrópica e desenvolvimento sustentável. In: Racionalidade ambiental: a reapropriação social da natureza. Tradução: Luiz Carlos Cabral. Rio de Janeiro: Civilização Brasileira, 2006.

LEFF, Enrique. Pensar a complexidade ambiental. In: Epistemologia ambiental. Tradução: Sandra Valenzuela. São Paulo: Cortez, 2001.

MORIN, Edgar. Os sete saberes necessários à educação do futuro. Tradução: Catarina Eleonora F. da Silva e Jeanne Sawaya. São Paulo: Cortez, Brasília, DF: UNESCO, 2000.

NASCIMENTO, Elimar Pinheiro do. Trajetória da Sustentabilidade: do ambiental ao social, do social ao econômico. Estudos Avançados. Vol. 26, nº 74. São Paulo, 2012.

QUADROS, Karin Esemann. A concepscão de meios e ambientes para a criança: uma perspectiva bolística. Disponível em $<<$ http://www.portalanpedsul.com.br/admin/uploads/1998/Educacao e questoes ambientais/Trabalho/05 24 49 A CONCEPCAO DE MEI OS E AMBIENTES.pdf $>>$. Acesso em: 27 de maio de 2013. 
RICHTER, Daniela; REIS, Suzéte da Silva. O direito ambiental e sua proteção jurídica sob a ótica dos direitos bumanos e da ação da juventude. Disponível em $<<$ http://www.conpedi.org.br/manaus/arquivos/anais/salvador/suzete d a silva reis.pdf $>>$. Acesso em: 05 de maio de 2013.

SANTOS, Boaventura de Sousa. Da ciência moderna ao novo senso comum. In: - Para um novo senso comum: a ciência, o direito e a política na transição paradigmática. 3a ed. São Paulo: Cortez, 2006.

SANTOS, Boaventura de Sousa. Ecologia dos Saberes. In: - $A$ gramática do tempo: para uma nova cultura política. São Paulo: Cortez, 2006 (Coleção para um novo senso comum, vol. 4).

SANTOS, Milton. Por uma outra globalização: do pensamento único à consciência universal. 20a ed. Rio de Janeiro: Record, 2011.

SARMENTO, Manuel Jacinto. Gerações e Alteridade: Interrogações a partir da Sociologia da Infância. In: Educ. Soc., Campinas, vol. 26, n. 91, p. 361-378, Maio/Ago. 2005.

SILVA, Maria José Albuquerque da; BRANDIM, Maria Rejane Lima. Multiculturalismo e Educação: em defesa da diversidade cultural. Revista Diversa, Ano I n²1. p. 51 - 66, Jan / Jun 2008.

SILVA, Winnie Gomes da; HIGUCHI, Maria Inês Gasparetto; FARIAS, Maria Solange Moreira de. As contribuições da Juventude na disseminação de ações sustentáveis no ambiente familiar. S/L: s/e, s/d.

VIEIRA, Ricardo Stanziola; SANTOS, Volney Campos dos. Direitos da criança e do adolescente e desenvolvimento social sustentável: uma perspectiva socioambiental para uma proposta teórico-prática de cidadania e novos direitos. Disponível em

$<<$ http://www.conpedi.org.br/manaus/arquivos/anais/manaus/direito e politica ricardo s vieira e volney dos santos.pdf $>>$. Acesso em: 05 de maio de 2013. 